\title{
Plasma Corticosteroids in Healthy Twin Pairs
}

\author{
J. D. MAXWELL, J. A. BOYLE, W. R. GREIG, and W. W. BUCHANAN \\ From the University Department of Medicine, and Centre for Rheumatic Diseases, Royal Infirmary, Glasgow
}

Three different but related mechanisms influence corticosteroid secretion by the normal human adrenal cortex. Under basal conditions the concentration of plasma cortisol and the secretion of pituitary ACTH constitute a negative feedback system through which fluctuations in plasma cortisol concentration are minimized. Plasma cortisol levels are, however, higher in the morning than at night because of a diurnal rhythm in the rate of ACTH secretion. Both negative feedback and diurnal rhythm may be overcome by the raised steroid secretion mediated in response to stress which causes great increase in ACTH output, and results in plasma cortisol levels much above those found in basal conditions (James, Landon, and Fraser, 1968). A unified hypothesis to explain the performance of the adrenal cortex under both normal and stressful conditions has been proposed by Yates and Urquhart (1962) who suggested that plasma cortisol levels were regulated by a negative feedback control system which had a variable setpoint.

In humans great variations in corticosteroid metabolism (for example the acceleration of corticosteroid removal in hyperthyroidism, or the impairment of corticosteroid removal in liver disease or myxoedema) are not accompanied by large changes in plasma corticosteroid concentration. This stability denotes effective control of plasma corticosteroid levels by correction of the adrenal cortical secretion rate for alterations in corticosteroid metabolism.

The effect of environmental factors on adrenal cortical activity-for example the increase in adrenal corticosteroid secretion and increase in plasma cortisol levels in response to stress, or the alteration in the diurnal rhythm by variation in the activity cycle or length of day-is well recognized. But there is very little information available on the possible contribution of genetic factors in the control of pituitary-adrenocortical activity, or of plasma

Received January 7, 1968. cortisol levels in man. Great variations in plasma cortisol levels have been found at a given time of day in different individuals thought to be in a similar physiological state, while plasma cortisol levels are relatively constant in any one subject. This interperson variation and intraperson constancy has not been adequately explained. It does not appear to be due to differences in age, sex, weight, or build, but genetic factors might be important.

Racial differences in urinary steroid excretion have been reported by several workers. Politzer and Tucker (1958) and Edozien (1960) found low values for the excretion of 17-ketosteroids and 17ketogenic steroids in South African Bantus, and Nigerian males. Simpson (1965) reported differences in urinary 17-hydroxycorticosteroid excretion between European and Equatorial Amerindians. However, urinary steroid levels give an imprecise indication of adrenocortical activity, and the finding that plasma cortisol levels in East African males are similar to those found in other communities (Leonard, 1965) suggests that interracial differences are not important as far as the control of plasma cortisol levels is concerned.

In the present investigation the importance of genetic influences on the pituitary-adrenal axis has been studied by measuring plasma corticosteroid levels in healthy human twin pairs (Becker, 1967).

\section{Material and Methods}

Twins Studied. In all, 142 twin pairs from the Glasgow and West of Scotland area volunteered in response to appeals through the local press, radio, and television for healthy twin pairs. Each twin was interviewed and examined simultaneously, in either the afternoon or early evening. None of the twins had clinically apparent disease, nor were any known to be on steroid therapy. All the twins had normal blood pressure readings (Downie et al., 1969). Table I shows the segregation of the 142 twin pairs according to their sex and zygosity. It can be seen that there was a relative excess of monozygotic (MZ) female twin pairs, and that the majority of twins were young. The mean age and age ranges were, however, similar in all groups. 
Determination of Zygosity. The methods used to determine the zygosity of the twins have been described elsewhere (Greig et al., 1967). These methods are not completely accurate but give a likelihood of a correct diagnosis of monozygosity of greater than $90 \%$ in every twin pair accepted as being monozygous in the present study. In the case of dizygous (DZ) twins, however, the likelihood of a correct diagnosis of zygosity was $100 \%$, as zygosity was only diagnosed when there was unequivocal evidence of genetically determined phenotype difference such as variation in facial appearance, fingerprint pattern, hair, or iris colour, or blood group antigen.

Measurement of Plasma Corticosteroids. After determination of blood pressure, venous blood samples were taken from each twin at the same time. The blood was taken into lithium heparin tubes, centrifuged, and the supernatant plasma retained and stored at $0^{\circ} \mathrm{C}$. Plasma corticosteroids were measured as the 11-hydroxycorticosteroids using the fluorimetric method described by Mattingly (1962). Though, in man, cortisol is the principal free 11-OHCS in plasma, corticosterone is present in much smaller amounts and is also measured by this method. In this study the term plasma corticosteroids thus refers to the total 11-hydroxycorticosteroids.

Statistical Analysis. The differences between the two members of the pairs of twins are expressed as mean intrapair variances, and can be calculated from the expression $\sum x^{2} / n$, where $x$ is the difference between the two members of a pair of twins (in this instance in the plasma corticosteroid level), and $n$ is equal to the number of pairs of twins. The method used in this study contrasts the mean intrapair variance of plasma corticosteroid levels observed in $M Z$ (genetically identical) twin pairs, with the mean intrapair variance of plasma corticosteroid levels in the like-sex DZ (genetically nonidentical) twin pairs. The variance ratio is calculated from a comparison of the different mean intrapair variances, and its significance is assessed using the $F$ distribution (Osborne and DeGeorge, 1959).

\section{Results}

The results are summarized in Tables I, II, and III. The data for unlike-sex dizygotic twin pairs is included in the Tables, but not used in the study, as interpretation of the results is made difficult by the sex difference in this group of twin pairs.

Mean and Range. The mean plasma corticosteroid levels were 14.12 and $14.79 \mu \mathrm{g} . / 100 \mathrm{ml}$. for the $\mathrm{MZ}$ and $\mathrm{DZ}$ female twin pairs, respectively, and 16.22 and $11.96 \mu \mathrm{g} . / 100 \mathrm{ml}$. for the $\mathrm{MZ}$ and $\mathrm{DZ}$ male twin pairs, respectively.

The range of plasma corticosteroid levels in female twins was $5.5-28.5 \mu \mathrm{g} . / 100 \mathrm{ml}$. and in male twins $3 \cdot 5-37 \cdot 0 \mu \mathrm{g} . / 100 \mathrm{ml}$. (Table I).

Intrapair Variances. The results are first presented for all the male and female twins taken as a whole (Table I), and then analysed separately for male and female twins living together, and those separated for more than one year (Table II).

The intrapair variance for plasma corticosteroids of 12.62 for all the $\mathrm{MZ}$ female twin pairs contrasts with the intrapair variance of 32.40 in the $\mathrm{DZ}$ female twin pairs. This comparison yields an $F$ ratio of 2.57 which is significant at the less than 1 in a 100 $(p<0.01)$ level (Table III). However, examination of the data for males shows that the intrapair variance for $M Z$ male twin pairs $(30.47)$ was higher than the intrapair variance for the $\mathrm{DZ}$ male twin pairs $(18 \cdot 68)$, which is clearly not significant of a genetic component (Table III).

In Table II the intrapair variance of plasma corticosteroids in twins living together in the same household, and for twins separated from each other for longer than one year, is documented. For

TABLE I

RESULTS OF PLASMA CORTICOSTEROID DETERMINATION IN 142 TWIN PAIRS

\begin{tabular}{|c|c|c|c|c|c|c|c|c|c|}
\hline \multirow{2}{*}{\multicolumn{2}{|c|}{ Twin Group }} & \multirow{2}{*}{$\begin{array}{l}\text { No. of } \\
\text { Twin } \\
\text { Pairs }\end{array}$} & \multicolumn{3}{|c|}{ Age (yr.) } & \multicolumn{4}{|c|}{ Results Plasma Corticosteroid } \\
\hline & & & Mean & $\mathrm{SD}^{\star}$ & Range & Mean & SD & Range & $\begin{array}{c}\text { Intrapair } \\
\text { Variance }\end{array}$ \\
\hline $\mathbf{M Z}$ & $\begin{array}{l}\text { Female } \\
\text { Male }\end{array}$ & $\begin{array}{l}46 \\
20\end{array}$ & $\begin{array}{l}21 \\
25\end{array}$ & $\begin{array}{l}10 \cdot 9 \\
16 \cdot 8\end{array}$ & $\begin{array}{l}12-66 \\
13-65\end{array}$ & $\begin{array}{l}14 \cdot 12 \\
16 \cdot 22\end{array}$ & $\begin{array}{l}5 \cdot 28 \\
8 \cdot 18\end{array}$ & $\begin{array}{l}5 \cdot 9-28 \cdot 5 \\
3 \cdot 5-37\end{array}$ & $\begin{array}{l}12 \cdot 62 \\
30 \cdot 47\end{array}$ \\
\hline $\mathrm{DZ}$ & $\begin{array}{l}\text { Female } \\
\text { Male }\end{array}$ & $\begin{array}{l}23 \\
18\end{array}$ & $\begin{array}{l}22 \\
21\end{array}$ & $\begin{array}{l}15 \cdot 6 \\
10.9\end{array}$ & $\begin{array}{l}12-70 \\
12-47\end{array}$ & $\begin{array}{l}14.79 \\
11.96\end{array}$ & $\begin{array}{l}5 \cdot 87 \\
5 \cdot 11\end{array}$ & $\begin{array}{l}5 \cdot 5-28 \cdot 3 \\
4 \cdot 0-23\end{array}$ & $\begin{array}{l}32.40 \\
18.68\end{array}$ \\
\hline $\mathrm{DZ}$ & Unlike sex & 35 & 19 & $11 \cdot 4$ & $12-64$ & $12 \cdot 8$ & $5 \cdot 11$ & $4 \cdot 4-28 \cdot 5$ & $18 \cdot 34$ \\
\hline
\end{tabular}

$\star \mathrm{SD}$, standard deviation.

t See text for explanation of how this function was calculated. 
TABLE II

\begin{tabular}{|c|c|c|c|c|c|c|c|c|c|c|c|}
\hline \multicolumn{7}{|c|}{$\begin{array}{l}\text { MEAN INTRAPAIR VARIANCE OF PLAS } \\
\text { TOGETHER AND IN TWINS LIVING AP } \\
\qquad \begin{array}{r}\text { Twins Together }\end{array}\end{array}$} & \\
\hline \multirow{2}{*}{\multicolumn{2}{|c|}{ Twin Group }} & \multirow{2}{*}{$\begin{array}{l}\text { No. of } \\
\text { Twin } \\
\text { Pairs }\end{array}$} & \multicolumn{3}{|c|}{ Age (yr.) } & \multirow{2}{*}{$\begin{array}{l}\text { Intrapair } \\
\text { Variancet } \\
\text { Plasma } \\
\text { Cortico- } \\
\text { steroid }\end{array}$} & \multirow{2}{*}{$\begin{array}{l}\text { No. of } \\
\text { Twin } \\
\text { Pairs }\end{array}$} & \multicolumn{3}{|c|}{ Age (yr.) } & \multirow{2}{*}{$\begin{array}{l}\text { Intrapair } \\
\text { Variance } \\
\text { Plasma } \\
\text { Cortico- } \\
\text { steroid }\end{array}$} \\
\hline & & & Mean & Range & $\mathrm{SD}^{\star}$ & & & Mean & Range & SD & \\
\hline Female & $\begin{array}{l}\mathrm{MZ} \\
\mathrm{DZ}\end{array}$ & $\begin{array}{l}37 \\
18\end{array}$ & $\begin{array}{l}18 \\
17\end{array}$ & $\begin{array}{l}12-50 \\
12-70\end{array}$ & $\begin{array}{r}6 \cdot 8 \\
13 \cdot 2\end{array}$ & $\begin{array}{l}13 \cdot 32 \\
40 \cdot 22\end{array}$ & $\begin{array}{l}9 \\
5\end{array}$ & $\begin{array}{l}34 \\
40\end{array}$ & $\begin{array}{l}19-66 \\
27-50\end{array}$ & $\begin{array}{r}14 \cdot 6 \\
9 \cdot 8\end{array}$ & $\begin{array}{l}9 \cdot 72 \\
4 \cdot 26\end{array}$ \\
\hline Male & $\begin{array}{l}\mathrm{MZ} \\
\mathrm{DZ}\end{array}$ & $\begin{array}{l}14 \\
13 \\
\end{array}$ & $\begin{array}{l}16 \\
15\end{array}$ & $\begin{array}{l}13-21 \\
12-22\end{array}$ & $\begin{array}{l}2 \cdot 5 \\
2 \cdot 6\end{array}$ & $\begin{array}{l}27 \cdot 29 \\
12 \cdot 89\end{array}$ & $\begin{array}{l}6 \\
5\end{array}$ & $\begin{array}{l}48 \\
37\end{array}$ & $\begin{array}{l}30-65 \\
28-47\end{array}$ & $\begin{array}{r}14 \cdot 1 \\
7 \cdot 3\end{array}$ & $\begin{array}{l}37 \cdot 89 \\
33 \cdot 72\end{array}$ \\
\hline $\mathrm{DZ}$ & Unlike sex & 31 & 16 & $12-55$ & $7 \cdot 9$ & $18 \cdot 90$ & 4 & 38 & $27-64$ & $16 \cdot 2$ & 13.97 \\
\hline
\end{tabular}

$\star$ SD, standard deviation.

+ See text for explanation of how this function was calculated.

TABLE III

SIGNIFICANCE VALUES FOR OBSERVED INTRAPAIR VARIANCES OF PLASMA CORTICOSTEROIDS IN MALE AND FEMALE TWINS

\begin{tabular}{|c|c|c|c|c|c|}
\hline & Twin $C$ & roup & $\begin{array}{l}\text { Intrapair } \\
\text { Variance }\end{array}$ & F Ratio & P Value \\
\hline \multirow{2}{*}{ All Twins } & Female & $\begin{array}{l}\mathrm{MZ} \\
\mathrm{DZ}\end{array}$ & $\begin{array}{l}12 \cdot 62 \\
32 \cdot 40\end{array}$ & $2 \cdot 57$ & $<0.01$ \\
\hline & Male & $\begin{array}{l}\mathrm{MZ} \\
\mathrm{DZ}\end{array}$ & $\begin{array}{l}30 \cdot 47 \\
18 \cdot 68\end{array}$ & 0.61 & NS \\
\hline \multirow{2}{*}{$\begin{array}{l}\text { Twins living } \\
\text { together }\end{array}$} & Female & $\begin{array}{l}\mathrm{MZ} \\
\mathrm{DZ}\end{array}$ & $\begin{array}{l}13 \cdot 32 \\
40 \cdot 22\end{array}$ & 3.05 & $<0.01$ \\
\hline & Male & $\begin{array}{l}\mathrm{MZ} \\
\mathrm{DZ}\end{array}$ & $\begin{array}{l}27 \cdot 29 \\
12 \cdot 89\end{array}$ & 0.47 & NS \\
\hline \multirow{2}{*}{ Twins living apart } & Female & $\begin{array}{l}\mathrm{MZ} \\
\mathrm{DZ}\end{array}$ & $\begin{array}{l}9 \cdot 72 \\
4 \cdot 26\end{array}$ & 0.43 & NS \\
\hline & Male & $\begin{array}{l}\mathrm{MZ} \\
\mathrm{DZ}\end{array}$ & $\begin{array}{l}37 \cdot 89 \\
33 \cdot 72\end{array}$ & 0.88 & NS \\
\hline
\end{tabular}

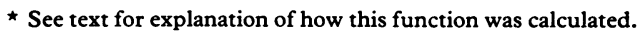

female twin pairs living together the mean intrapair variance for $\mathrm{MZ}$ twins was 13.32 and for $\mathrm{DZ}$ twins was $40 \cdot 22$. This difference yields an $F$ ratio of 3.05 which is highly significant $(p<0.01)$ (Table III). When $M Z$ and $\mathrm{DZ}$ female twins living apart are compared it is seen that the intrapair variance for $M Z$ females (9.72) is higher than the intrapair variance for $\mathrm{DZ}$ females $(4 \cdot 26)$. There is thus no evidence for genetic control of plasma cortisol in this group, though the numbers are small.

In males living together the intrapair variance of $\mathrm{MZ}$ twins was $27 \cdot 29$, while for $\mathrm{DZ}$ twins it was only 12.89. There is thus clearly no evidence for a genetic factor. Comparison of intrapair variances in $\mathrm{MZ}$ and $\mathrm{DZ}$ male twins living apart also failed to show any significant genetic component in the control of plasma corticosteroids. The number of separated and non-separated twins studied was small, but the results were no different from those obtained when all males were studied together.

\section{Discussion}

Both genetic and environmental factors have been shown by earlier twin studies to be important in the control of biochemical parameters such as serums cholesterol (Pikkarainen, Takkunen, and Kulonen, 1966) and uric acid (Boyle et al., 1967). To our knowledge, however, there has been no previous? study of plasma corticosteroid levels in normal twins.

Our results show a significantly smaller intrapair variance in plasma corticosteroids in $M Z$ as compared to $\mathrm{DZ}$ female twin pairs. Before accepting this difference as evidence of genetic control, it should be considered whether the results could be explained by the $M Z$ twins sharing a more uniform environment than did the $\mathrm{DZ}$ twins. We consider this alternative explanation to be unlikely in the present study, as the significantly lower intrapair variance for plasma corticosteroid values in $\mathrm{MZ}$ females, compared with DZ females, was not matched by the findings in the $M Z$ and $\mathrm{DZ}$ male twins, and the vast majority of the twins of both sexes were young and living in the same home environment at the time of study.

It seems reasonable to conclude therefore that the smaller intrapair variance in the female $\mathrm{MZ}$ compared to $\mathrm{DZ}$ twins almost certainly reflects a fairly strong genetic control of the variation in plasma corticosteroid levels in females. The failure to show a genetic control of plasma corticosteroid levels in males does not mean that such control does not exist, but that it is likely to be weak 
and easily masked by the environmental factors already recognized as affecting plasma corticosteroids. Another factor that may have contributed to the failure to detect a genetic component in the control of plasma cortisol in males was the small number studied. In addition, a possible criticism of our method was the fact that blood samples were taken during the period (late afternoon/evening) when cortisol levels are normally low and thus relatively more vulnerable to experimental error.

The sensitivity of plasma corticosteroids to environmental factors is readily appreciated when the data for the various female twin groups are examined separately (Table III). In the female $M Z$ and like DZ twin pairs taken as a whole, a genetic component in the control of plasma corticosteroids is apparent, and this is also true, as might be expected, when the results for female twins living together are analysed. However, on comparing the intrapair variance of $\mathrm{MZ}$ and $\mathrm{DZ}$ female twins separated for more than one year, no such genetic component can be detected-presumably because the genetic effect is a modest one, and has been obscured by the environmental factors operating in this group.

The results of the present study pose further questions about the mechanisms controlling plasma corticosteroid levels. Why should a genetic component in the control of plasma corticosteroids be apparent in females but not so in males? The explanation for the apparently dominant role of environmental factors in the control of plasma corticosteroids in males may be a teleological onepossibly related to the requirement of the male for adrenocortical mechanisms readily responsive to stress and changing environmental situations. The more protected position of the female, on the other hand, might allow environmental mechanisms controlling adrenocortical secretion to play a less important role.

Finally, in what way could a genetic factor operate to regulate the plasma corticosteroid level? We have no information on this point but a possible mechanism may be via control of the level of the set-point of plasma cortisol, which in turn regulates the functioning of the negative feedback system. These suggestions are purely hypothetical, and further work is required before these questions can be answered.

\section{Summary}

Plasma corticosteroid levels were estimated by the fluorimetric method of Mattingley in 142 pairs of healthy twins from the Glasgow and West of Scotland area.

Calculation of the intrapair variances in monozygotic and dizygotic twins showed a significant genetic component in the control of variation in the plasma corticosteroid level in females. The study failed to detect a genetic component in males. The suggestion that environmental factors play a more important role in the regulation of plasma corticosteroid levels in males compared with females is discussed.

We are grateful for the co-operation of the many twins who took part in this survey.

The work was supported by a grant from the Arthritis and Rheumatism Council.

\section{REFERENCES}

Becker, K. L. (1967). The twin-study method in medicine and genetics. Postgrad. Med., 41, 603.

Boyle, J. A., Greig, W. R., Jasni, M. K., Duncan, A., Diver, M., and Buchanan, W. W. (1967). Relative roles of genetic and environmental factors in the control of serum uric acid levels in normouricaemic subjects. Ann. rheum. Dis., 26, 234.

Downie, W. W., Boyle, J. A., Greig, W. R., Buchanan, W. W., and Alepa, F. P. (1969). Relative roles of genetic and environmental factors in control of blood pressure in normotensive subjects. Brit. Heart f., 31, 21.

Edozien, J. C. (1960). Biochemical normals in Nigerians. Urinary 17-oxosteroids and 17-oxogenetic steroids. Lancet, 1, 258.

Greig, W. R., Boyle, J. A., Duncan, A., Nicol, J., Gray, M. J. B., Buchanan, W. W., and McGirr, E. M. (1967). Genetic and nongenetic factors in simple goitre formation. Evidence from a twin study. Quart. F. Med., 36, 175.

James, V. H. T., Landon, J., and Fraser, R. (1968). Some observations on the control of corticosteroid secretion in man. Mem. Soc. Endocrinol., 17, 141.

Leonard, P. J. (1965). Plasma-cortisol levels in East African subjects. Lancet, 1, 845.

Mattingly, D. (1962). A simple fluorimetric method for the estimation of free 11-hydroxycorticoids in human plasma. f. clin. Path., 15, 374.

Osborne, R. H., and DeGeorge, F. V. (1959). Genetic Basis of Morphological Variation, p. 25. Harvard University Press, Cambridge, Massachusetts.

Pikkarainen, J., Takkunen, J., and Kulonen, E. (1966). Serum cholesterol in Finnish twins. Amer. f. hum. Genet., 18, 115.

Politzer, W. M., and Tucker, B. (1958). Urinary 17-ketosteroid and 17-ketogenic steroid excretion in South African Bantu. Lancet, 2, 778.

Simpson, H. (1965). The daily adrenal rhythm in Equatorial Amerindians. F. Endocr., 32, 179.

Yates, F. E., and Urquhart, J. (1962). Control of plasma concentrations of adrenocortical hormones. Physiol. Rev., 42, 359. 